\title{
Teachers Teaching Differently: A Qualitative Study of Implementation Fidelity to Professional Development
}

\author{
Michael E. Woolley ${ }^{1}$, Roderick A. Rose ${ }^{2}$, Micaela Mercado ${ }^{2}$ \& Dennis K. Orthner ${ }^{3}$ \\ ${ }^{1}$ School of Social Work, University of Maryland, Baltimore, Maryland \\ ${ }^{2}$ School of Social Work, New York University, New York, New York \\ ${ }^{3}$ Schools of Social Work and Education, University of North Carolina, Chapel Hill, North Carolina \\ Correspondence: Michael E. Woolley, School of Social Work, University of Maryland, Baltimore, Maryland, \\ USA. Tel: 1-410-706-7839. E-mail: mwoolley@ssw.umaryland.edu
}

Received: December 17, 2012 Accepted: December 31, 2012 Available online: January 21, 2013

doi:10.11114/jets.v1i1.48 URL: http://dx.doi.org/10.11114/jets.v1i1.48

\begin{abstract}
Intervention researchers in school settings often implement interventions that involve professional development to schoolteachers or other professional staff to implement school-based interventions. In terms of classroom interventions, teachers are the primary implementation agents; therefore, the fidelity of such interventions depends on teacher adoption and delivery. To understand and meet such fidelity challenges, we set to identify the contextual components and implementation mechanisms that contribute to the variation in teachers' perspectives and methods of implementing an experimental evaluation of CareerStart; an innovative intervention designed to increase student school engagement and achievement by advancing teacher use of career relevant instruction in the middle grades. The results of this study suggest teachers perceive CareerStart in three interrelated ways: their perceptions of the program's effectiveness on student outcomes; the degree to which the program is adaptable and compatible to their roles and responsibilities; and the effects of the school environment on their perceptions of the intervention. We conclude with a discussion of treatment fidelity effectiveness in school-based intervention programs.
\end{abstract}

Keywords: treatment fidelity, professional development, intervention research, middle school, school engagement, school-based intervention, evidence-based practice, implementation

\section{Introduction}

Intervention researchers working in school settings recognize that teachers and educational professionals can play vital roles in the successful implementation of school- and classroom-based interventions. In particular, layering interventions on existing structural and social environments such as found in schools present unique challenges to researchers. Further, difficulties arise from the complexities associated with the school as: 1) a "host" research or practice setting for intervention researchers who are not teachers, 2) a learning environment for youth, as well as 3) a workplace for teachers and staff (Orthner, Cook, Sabah \& Rosenfeld, 2006; Woolley, 2007). Successful implementation of interventions designed to change, for example, student engagement in school, frequently involve changing selected aspects of work-related interactions and school or classroom contextual factors. This study explores how such complexities can compromise the fidelity of school-based interventions, which presents significant challenges to researchers who seek to design and implement interventions in school settings.

The potential value of understanding this complex layering effect on treatment fidelity presents significant implications for the growing volume of research focused on the impact of teaching strategies, the teacher-student relationship, and the learning climate in schools. Perry, Liu, and Pabian (2010) found that teacher support has a positive effect on student engagement, with higher levels of exposure predicting improved student academic performance. Likewise, Woolley and Grogan-Kaylor (2006), in a study including measures across three influential settings for students-home, neighborhood, and school-found teacher support to be the most influential environmental factor in predicting a student's sense of school coherence and academic performance. Orthner, Cook, Sabah and Rosenfeld (2006) reported in a cross-national study that enhancing the organizational learning environment of the classroom benefitted student behavior in the classroom and improved teacher morale 
and performance.

\subsection{Teacher Factors in Achievement}

A positive teacher-student relationship also helps facilitate student learning. In addition to fostering positive relationships, teachers have implemented pedagogical changes to facilitate student motivation and engagement in the learning process, especially through strategies that utilize contextual relevance in classroom lessons (Keller, 1983; Means, Jonasson, \& Dwyer, 1997). These changes can include strategies to increase the relevancy of instruction related to contemporary circumstances of students as well as future college and career opportunities. Relevancy of instruction improves students' sense of purpose, connection to their learning, and beliefs that their personal goals are attainable (Orthner, Akos, Rose, Jones-Sanpei, Mercado, Woolley, 2010). In order to increase relevant instruction school systems often encourage teachers to apply career exploration activities in their classrooms. This approach has been shown to have a positive impact on student engagement (Kenny \& Bledsoe, 2005).

Because teachers implement instructional interventions in their classrooms, implementation fidelity hinges on teacher adoption. Treatment fidelity is the capacity, ability, and extent to which teachers implement a program as it was intended (Fraser, Richman, Galinsky, \& Day, 2009; Tucker \& Blythe, 2008). In the case of CareerStart, we operationalize fidelity as extent of use of the prepackaged CareerStart lessons provided by the intervention to the teachers (while acknowledging that the use of career examples in pedagogy is not an uncommon strategy). Threats to fidelity include factors that lead to the diminution of consistent delivery of the core elements of an intervention, in the case of CareerStart, that means the use of the curriculum linked lessons. Still, there are many factors that can threaten treatment fidelity; therefore, researchers seek high levels of standardization through the development of strategies such as program manuals, professional development training, and requiring individuals implementing an intervention to demonstrate competence through an evaluation or certification in the delivery of an intervention (Tyler \& Blythe, 2008). Despite such efforts, researchers and teachers face a myriad of challenges to high fidelity service delivery.

In this study, we investigate teacher factors, which influenced CareerStart treatment fidelity by conducting focus groups with randomly selected teachers in several schools implementing CareerStart in 2006-07 and 2007-08. Our findings suggest that teachers' perceptions of the program, its compatibility to their roles and responsibilities, and the influence of the school environment have implications for education researchers working with teachers to implement changes in classrooms. We link our findings to the literature and propose that what we have found lends support to what other researchers have found regarding implementation fidelity with teachers and has implications for researchers and practitioners working in educational settings (Smith, Daunic, \& Taylor, 2007; Wehby, Maggin, Partin, \& Robertson, 2011; Zvoch, 2009).

\subsection{The Intervention: CareerStart}

Developed by an interdisciplinary research team in partnership with educators in both a university school of social work and school of education, and a school district, CareerStart is a curriculum-based intervention program designed to improve student engagement in school and prevent progressive student disengagement across the middle grades. CareerStart lessons were developed and peer reviewed by teachers under a rubric that linked the new lessons to current priority content in core middle school subject areas. After review by curriculum specialists, the lesson plans and resources were made available on line for $6^{\text {th }}, 7^{\text {th }}$ and $8^{\text {th }}$ grade core subject teachers.

\subsubsection{Student Engagement}

Two aspects of student engagement are targeted: 1) emotional engagement, which is characterized by a student valuing school, seeing school as important to his or her future, and feeling he or she can succeed at school, which theoretically leads to 2) behavioral engagement, which includes attending school, following the rules, and completing assignments (Fredricks, Blumenfeld, \& Paris, 2004). Substantial evidence indicates student emotional and behavioral engagement is positively associated with academic performance, persistence, and completion (Finn, 1993; Fredricks, Blumenfeld, \& Paris, 2004; Perry, 2008; Woolley \& Bowen, 2007). It is alarming, therefore, that current research indicates that student engagement typically declines across the middle and high school years for all students, including those at risk for school failure (Anderman, \& Midgely, 1997; Martin, 2009; Wigfield \& Tonks, 2002).

CareerStart was designed to advance student engagement by improving students' understanding of the relevance of their school coursework to jobs and careers that use the skills learned in the classroom, thereby influencing how students perceive their possible futures. It is an innovative program in a number of ways. First, it strives to 
reduce high school drop out by intervening at the middle school level when student disengagement from school experiences its greatest. In contrast, dropout programs are most often implemented in high schools, arguably after trajectories toward failure and dropout are already established. Second, rather than the intervention being implemented in a separate course or module, CareerStart intervenes directly within the core academic coursework of middle grade students: math, language arts, science and social studies courses. Third, teachers are the CareerStart practitioners, trained and provided with well-developed lessons and instructional materials by the implementation team. Finally, CareerStart is a universal strategy in that all middle school teachers across sixth, seventh, and eighth grades implement the lessons to all students, allowing each student to experience the intervention throughout the middle grades. Figure 1 depicts these innovative characteristics as well as an overview of the theoretical foundation informing intervention development and implementation.

Implementing CareerStart in middle schools involves wrestling with the layering effects and complexity of the school environment as both work and learning environments, as well as non-educators coming into a school and training teachers with the goal to change what they do in their classrooms, both of which can exacerbate challenges in achieving high implementation fidelity. This layering and complexity can be seen in the CareerStart theory of change logic model in Figure 1. In order to change student outcomes, the intervention involves changing teaching style and strategies, which is dependent on the organizational changes implemented by school principals.

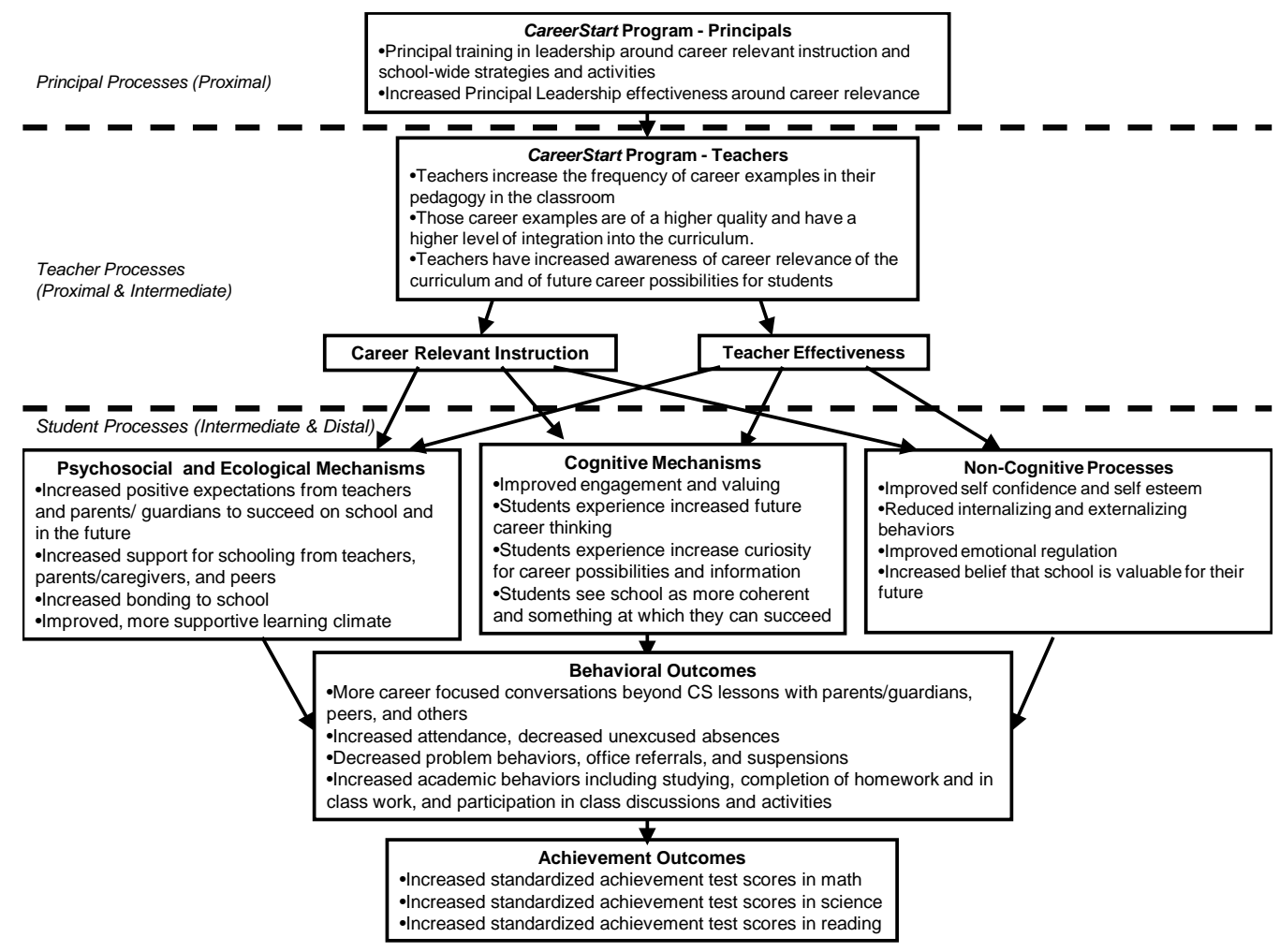

Figure 1. CareerStart Theory of Change Model

CareerStart training, resources and technical assistance equip teachers with example on-line lessons, and career-relevant instructional tools that help them relate classroom material to the ways in which adults in jobs and careers might apply such information. Research findings indicate CareerStart increases student academic achievement and reduces school disengagement and student misbehavior (Orthner, Jones-Sanpei, Rose, Mercado, Akos, 2010). The approaches teachers use to implement CareerStart are attributable to diverse factors such as their levels of experience (Rose, Woolley, Akos, Orthner, Mercado, \& Jones-Sanpei, 2012), preferred teaching styles, acceptance of the intervention model, and the diverse characteristics and needs of their students.

\subsubsection{Prior Research on CareerStart}

Previous research emerging from a randomized control trial previously found positive effects from CareerStart. Those effects demonstrated that CareerStart: 1) effectively advances teacher use of career relevant material in their lessons (Rose et al., 2012); 2) improves the value students perceive in their education as important to their 
futures (Orthner, Jones-Sanpei, Akos, \& Rose, 2013); and 3) improves student achievement on math end-of-grade tests (Orthner, Rose, \& Mercado, 2009; Woolley et al., in review). Further, findings with respect to increased teacher use of CareerStart materials illustrated that: a) on average teachers successfully implemented the treatment in their lessons; b) there were variations at the teacher level in this implementation; and c) closer examination of the teacher-level sources of this variation in fidelity are central to understanding how it can be improved.

\subsubsection{Teacher Fidelity}

Quantitative data underscores this variation. Table 1 shows teacher fidelity as measured by the proportion of lessons delivered each year between 2006-07 and 2008-09. For example, the proportion of lessons implemented in 2008-09 (64\%) exceeded the proportion of lessons delivered in 2006-07.

Table 1. Teacher Fidelity by Proportion of Lessons Delivered

\begin{tabular}{lllll}
\hline Year & Mean & $\begin{array}{l}\text { Standard } \\
\text { Deviation }\end{array}$ & Skewness & Kurtosis \\
\hline $2006-07$ & 0.58 & 0.26 & 0.06 & -1.29 \\
$2007-08$ & 0.54 & 0.24 & -0.08 & -0.75 \\
$2008-09$ & 0.64 & 0.24 & -0.33 & -0.65 \\
\hline
\end{tabular}

The distributions of lessons taught for each cohort are illustrated in Figures 2, 3, and 4. Across the three years, the percent of teachers who taught at least five lessons increased. These graphs illustrate how treatment fidelity changes over time, providing important information to understand the implementation process in the program.

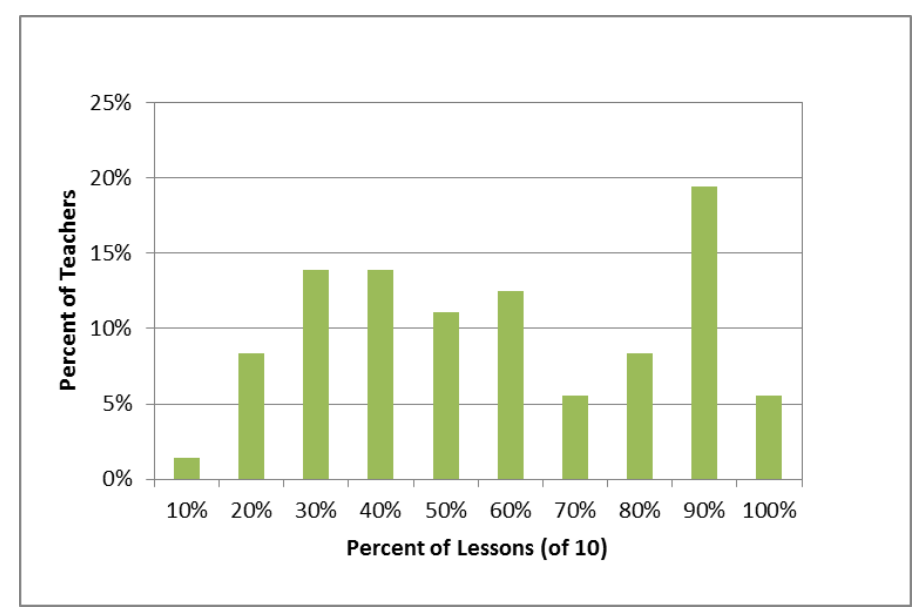

Figure 2. Teacher Fidelity in Year One

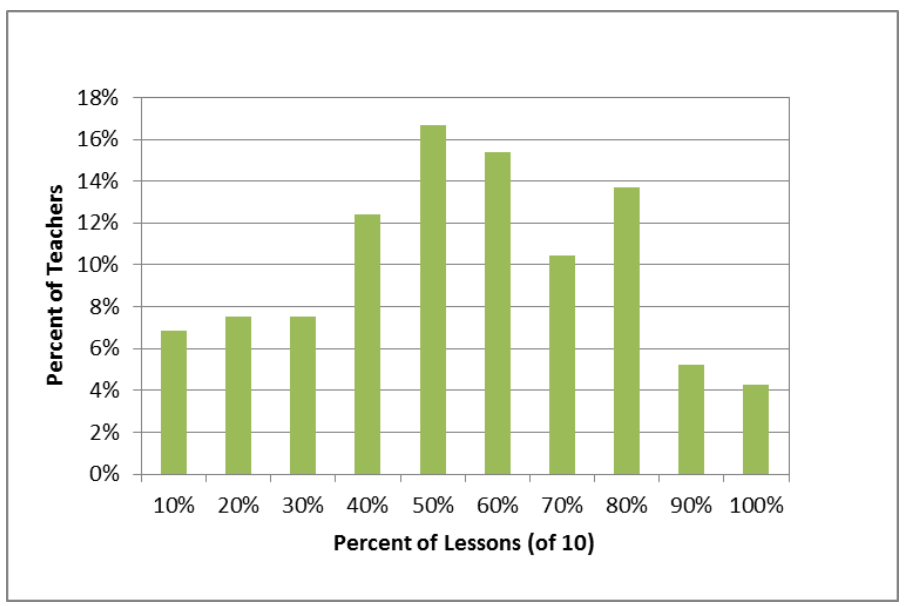

Figure 3. Teacher Fidelity in Year Two 


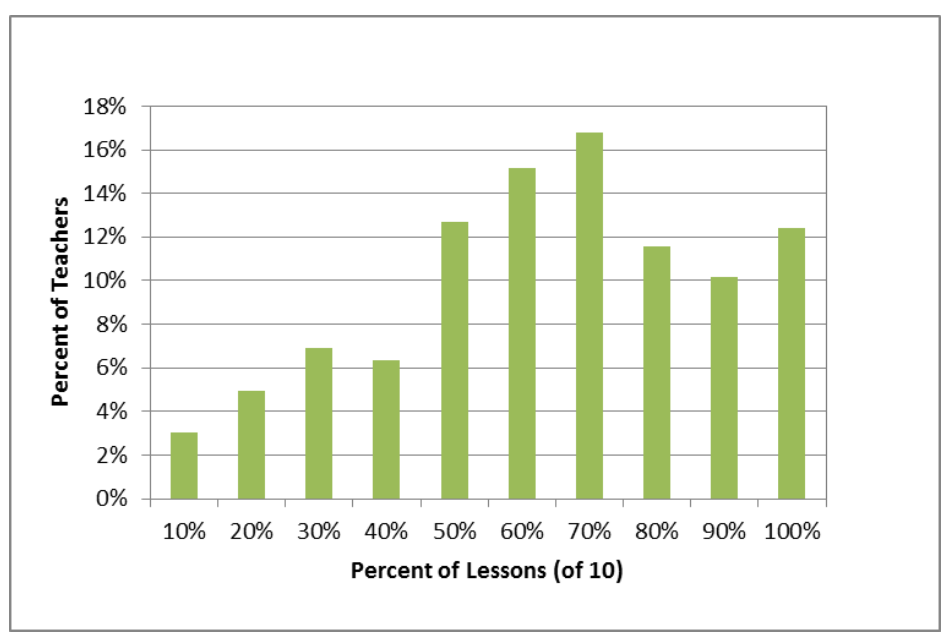

Figure 4. Teacher Fidelity in Year Three

\subsection{Treatment Fidelity}

Treatment fidelity is the extent to which program implementation consistently represents the intended model (Fraser, Richman, Galinsky, \& Day, 2009). Treatment fidelity in school-based interventions is monitored using both qualitative and quantitative methods to ensure students are receiving intended quality services (O'Hare, 2005). Examples of qualitative methods include case analyses, direct observational studies, or process assessments (O'Hare, 2005); with examples of quantitative methods include standardized questionnaires or surveys. Measuring the implementation process also gauges internal validity, that is, the extent to which the level of confidence researchers can assert that observable differences in outcomes—or lack thereof-were due to the intervention and not extraneous factors (Tucker \& Blythe, 2008).

However, too few research studies in school settings assess treatment fidelity. In a review of fifty-five school-based intervention studies identified by computer searches of the Education Resources Information Center (an abstract database commonly known as ERIC) and PsycINFO (an abstract database maintained by the American Psychological Association), 27 percent of published articles between 1975 and 2002 discussed treatment fidelity (Mooney, Epstein, Reid, \& Nelson, 2003). Although some studies that assessed fidelity also implemented strategies to enhance treatment fidelity, there appears to be sparse research on the use of treatment fidelity findings to improve treatment fidelity (Tucker and Blythe, 2008). These finding underscore the need for more attention to treatment fidelity in educational research as a necessary component for establishing evidence-based practices in education (McLeod, \& Southam-Gerow 2009; Mowbray, Holder, Teague, \& Bybee, 2003; Smith, Daunic, Taylor, 2007). Below, we describe two common components of treatment fidelity monitored in treatment implementations. Such data can also be effective for understanding participants' implementation methods, strengthening treatment fidelity protocols, and informing subsequent analyses and implementations.

\subsubsection{Contextual Factors}

In evaluating treatment fidelity, the implementation context often helps explain the degree to which implementation processes have an effect on treatment outcomes. In a meta-analysis of 81 studies, Durlak and DuPre (2008) identified 23 contextual factors that influenced implementation and situated those factors in three contextual categories: 1) community factors, 2) provider characteristics, and 3) intervention characteristics (Durlak \& DuPre, 2008). Community factors affect an intervention by means of such dynamics as politics, funding, or policies. For example, the successful implementation of a multi-school intervention program may be conditional on school officials' ability to petition for funding of the intervention through political support. School officials include the superintendent, principals, teachers and other school administrators, who are in the position to facilitate or delay implementation.

The second contextual category includes teachers' characteristics including perceptions of the intervention, beliefs about the need for the intervention, self-efficacy, teaching experience, and skill competence. For example, experienced teachers, already having had years of teaching experience and feeling skilled with numerous teaching strategies, may be more reluctant to change their established teaching practices, thus affecting treatment 
adherence. However, compared to seasoned teachers, novice teachers may respond favorably to an intervention they assume may help strengthen their skills and add to their repertoire of teaching practices (Stein et al., 2008). Teachers with positive perceptions of an intervention may demonstrate confidence, consequently affecting their level of adherence and contribution to overall fidelity compared to teachers with low opinion of the intervention (Durlak \& DuPre, 2008). This suggests researchers' understanding of the variation of teachers' characteristics is an important dimension of prior intervention implementation.

The last contextual category is intervention characteristics, which refers to the ease in which teachers can adapt the intervention to their needs and the extent to which the intervention is compatible with their roles, responsibilities, priorities, and the mission of the organization. An intervention that is adaptable to teachers suggests treatment fidelity is feasible when the components of the intervention complement their competencies. Overall, Durlak and DuPre (2008) suggest that treatment fidelity may be attainable and sustained when intervention processes fit the organizational context, in that the components align with both teachers' characteristics and the established systems and structure in which teachers work.

\subsubsection{Social Validity}

Social validity refers to both teachers' level of acceptance of an intervention and perceptions of intervention effectiveness in the classroom (Carter \& Pesko, 2008). However, educators' acceptance of school-based interventions is a sparsely researched area (Carter \& Pesko, 2008). The relationship between social validity and implementation fidelity is an extension of Wolf's (1978) research on the importance of seeking feedback from those who are in the role of implementing a treatment in order to understand a program's social significance. Wolf (1978) explained that changes in behavior assessed by an objective measure-for example direct observation utilizing a reliable instrument-may contradict for example, a teacher's report of the effectiveness of the program. For example, a child in a treatment program may show slight improvement in behavior, but feedback from the teacher may indicate significantly higher improvement. In this case, the difference between teacher feedback and the objective behavior score underlines Wolf's contention that intervention effectiveness is contingent on the social validity of the teacher.

Whereas Wolf discusses parents' social validity, here the connotation applies to the teacher, as the direct consumer, although not the eventual target of the intervention. Following this context, social validity refers to the teacher's subjective perception of the acceptability and feasibility of the procedures, and the value of the effects of the intervention (Wolf, 1978). For example, the application of intervention strategies (e.g., low adherence to a particular lesson) likely implemented by teachers' in their teaching practices may emerge from their perceptions of the intervention.

For teachers, one aspect of intervention feasibility is the extent to which the proposed intervention complements existing teaching practices (Carter \& Pesko, 2008). Rather than competing for teachers limited time, energy, and resources, or expecting them to exceed their roles and responsibilities, intervention practices that match classroom dynamics positively influence teachers' decisions to accept and adhere to a new intervention protocol (Carter \& Pesko, 2008). For example, in an evaluation of a school-based violence prevention program, Biggs and colleagues (2008) examined the social validity teachers placed on a particular intervention and its effect on teachers' decisions to implement the program. The researchers assumed social validity to be a function of perceived fit of the intervention with existing teaching practices. In measuring social validity, these researchers assessed: a) teachers' acceptability of the program; b) the degree to which their attitudes and belief systems aligned with the purpose of the intervention; and c) their perceptions of the effectiveness of the intervention (Biggs et al., 2008). Findings suggested teachers' level of new program acceptability and adherence aligned with the ease to which teachers felt that program components could be incorporated into their classroom routines, as opposed to representing discrete new classroom activities. Further, teachers' perceptions of the acceptability and usefulness of an intervention were significantly associated with program fidelity (Biggs et al., 2008). Interestingly, teachers' reports of the utility of the intervention increased significantly over time. These assessments also provided opportunities for teachers to comment on the intervention. Although most comments were positive, teachers' expressed concerns regarding the limited time allocated for collecting data for the intervention, and the perceived unnecessary requirements to change some of their teaching practices.

In a report of a similar research endeavor, Martens and McIntyre (2009) discussed the importance of evaluating educators' acceptability of an intervention. Acceptability here refers to the match between the characteristics of the intervention and teachers' own perceptions of its appropriateness and value (Martens \& McIntyre, 2009). The authors contend assessing practitioners' willingness to implement a program is as important as demonstrating treatment effectiveness. They explain practitioners may be more likely to respond positively to the intervention 
(e.g., increased levels of program commitment, higher rate of implementation fidelity, sustainability of program protocol over time) when educators' perceive an intervention as useful. Such research findings reinforce the layering effect and two level nature-teachers in their work environment and students in their learning environment — of the school as a setting for intervention research discussed above. However, Martens and McIntyre (2009) contend that acceptability does not necessarily yield consistent and sustainable implementation of intervention protocols by teachers. To remedy declining fidelity among teachers, continuous support and reinforcement, monitoring, and feedback are suggested methods for ensuring implementation integrity over time (Martens \& McIntyre, 2009).

Assessing teacher acceptability helps gauge the likely success of the implementation of an intervention. According to Chafouleas, Briesch, Riley-Tillman, and McCoach (2009), practitioners' responses to an intervention as "appropriate, fair, and reasonable" can be assessed, especially when relevant, appropriate modifications to the intervention are undertaken to strengthen teacher acceptability and treatment effectiveness (Chafouleas, et al., 2009). However, Chafouleas and colleagues (2009) also note that attaining high levels of acceptability alone does not necessarily result in teachers' effective use of the intervention program or its components. For example, in a multi-component drug prevention program evaluated by Stead and colleagues (2007), teachers' maintained an acceptable level of fidelity despite not understanding the rationale for conducting specific practices that were outlined in the intervention model. Qualitative interviews indicated that teachers exercised professional discretion and modified or excluded lesson components as they grew familiar with the intervention.

The contention that training and other forms of professional skill development are essential for ensuring fidelity has been widely researched, concluding that there is a positive correlation between training and high levels of fidelity (Stead et al., 2007). For example, Stead and colleagues (2007) concluded that time constraints in teachers' ability to deliver quality lessons, teachers' concerns about classroom disruptions during interactive assignments, and teachers' recognition of their limited content expertise were factors affecting their responses to the effectiveness of a new intervention (Sobeck, 2006). Further, program complexity appears to be associated with implementation, in that teachers may be less likely to implement complex interventions with high fidelity (Sobeck, 2006). In view of the challenges of maintaining treatment fidelity, in this study we explore the function of contextual factors and social validity on treatment fidelity of an intervention built around professional development training of middle grades teachers.

\section{Method}

\subsection{Sample}

In November 2008, qualitative data were collected from teachers focused on the implementation of the CareerStart program in the teachers' classrooms. We randomly selected 30 seventh grade teachers for four focus groups in four different schools. The teachers provided feedback about their use of CareerStart lessons, both positive and negative, as well as responses that they heard from their students about career examples being offered in the classroom. Two trained researchers led all group discussions. Sessions were tape-recorded, transcribed, and narratives of the conversations entered into Atlas-ti, version 5, a qualitative analytic software package (Atlas Ti, v5, 2008).

\subsection{Data Analysis Strategy}

Grounded theory informed the analysis of the data collected in the current study. Grounded theory is a recursive inductive process used to analyze and classify text data, followed by data hypotheses and theories that emerge from the analytic process (Padgett, 1998). Atlas.ti software facilitated open coding and a hierarchical classification procedure for themes emerging from the data. Open codings were used to identify preliminary codes for the narrative data, to provide a process for making memos and notes related to the coding, and to classify those codes and notes into themes. Described as a "cognitive act of assigning a code" (Lofland \& Lofland, 1995), in this process data coders extract patterns related to events, key words, processes, and characters from the data, and then categorize them (Coffey, 2007). The grounded theories developed from this analysis were then compared to the literature previously described to triangulate these findings with what is already known about layering interventions in K-12 education settings.

\subsection{Data Analysis}

Members of the CareerStart research team initially read all transcriptions twice at two different time points for literal interpretation and application of low and high inference coding (Anastas, 2004). These inference codings subsequently tested to see if they verified relationships between themes. Coffey and Atkinson (1996) report that 
this procedure allows each quotation to derive two meanings, the immediate context to which it belongs, and the thematic information it provides. Subsequently, thematic categories were developed and integrated through these analyses (Weiss, 1994). Researchers documented coding procedures using memos. This technique allowed the research team to describe coding procedures. By recording the researchers' decision-making processes, revisions and discrepancies among raters were resolved.

\section{Findings}

The current findings illuminate the effects of contextual factors on treatment fidelity as well as the effects of teachers' perceptions of the social validity of the intervention on treatment fidelity. Three themes emerged from analytic process: 1) program factors, 2) individual factors, and 3) school community factors.

\subsection{Program Factors}

Programmatic factors consisted of two subcategories: adaptability of the intervention for implementation, and the compatibility of the intervention to teachers' role and responsibilities in the classroom. Teachers' level of adaptability varied between implementing the intervention as intended and modifying the intervention to meet contextual dynamics in the classroom. Teachers indicated two factors contributing to the variation of adaptability. In the first variation of adaptability, teachers discussed the time constraints they faced when implementing a CareerStart lesson. For example, a 7th grade teacher indicated that lessons had

...too much content, in particularly in the social studies and math. There are too many things to do in a lesson plan. In one [lesson], we have to take 60 minutes...every lesson for CareerStart has been drastically modified. And for 45-minutes class period that forces down a lot. And the overwhelming factor to a minimum and stick to a few basic concepts per lesson.

Similarly, a language arts teacher commented,

I am teaching writing, reading and vocabulary and CareerStart so my time is limited and when you are working with children in levels 1 and 2, when we want them in $4 \mathrm{~s}$, the time factor is there. When that lesson is good might give them a better basis to make decisions about their careers. I just didn't have time.

Many teachers' characterized lessons as having too much content, and one teacher described the successful implementation of a lesson as dependent on inconsistent available classroom time. For example, the implementation of math activities varied during the week, in that math teachers implemented activities on some days more than other days. Teachers explained that partial implementation was appropriate as long as students were exposed to the assigned math activity.

The second variation of adaptability was teachers' ability to modify lessons for their students. Teachers stated that although lessons were partially completed, they had the option of returning to a lesson to either review a concept, or continue that lesson later. As one teacher stated, "we can break them up in quarters." Teachers also explained that adaptability was in part the fit between a CareerStart lesson and a required subject unit. Although one teacher asserted a high level of adaptability of the lessons:

[The lessons] are more adaptable to various learners. Especially for our population we can illuminate this part, it is very adaptable, and we have that adaptability to do a part that gets the most of it or eliminate this part. So it is very adaptable.

However, other teachers expressed that sometimes matching a CareerStart lesson to a teaching unit was difficult, or that the lesson was not easy to implement across varying student-learning levels. Although some teachers stated that modifying the lessons was difficult, one teacher suggested success in personalizing a CareerStart lesson:

I generally find it more successful if you personalize it to what you are doing in your classroom, like instead of using a generic job application you adapt it to what you are doing.

Along similar lines, a group of $7^{\text {th }}$ grade math teachers used CareerStart math lessons as "a good jumping off point for discussion and added more content to classroom discussions". Teachers commented positively on their ability to modify lessons; however, one teacher suggested problems with modification, in particular, partitioning the lesson:

This is not a day's lesson for us. If [students] reading abilities are limited they see all those words and they shut down. So, I do bits and pieces but then the problem with that is that the sequence is lost and absentees [miss parts of the lesson]. 
In general, teachers agreed that the lessons were flexible and easy to adapt to various classroom academic levels, but found it challenging to ensure students learned the material efficiently.

Along with issues of adaptability, the theme of compatibility between the intervention and teachers' roles and responsibilities also emerged from the data. As previously indicated, teachers were responsible for managing their time efficiently to ensure the intervention was implemented as intended. As one teacher indicated, implementing lessons in classroom periods lasting 45-minutes did not match established teaching schedules. An example of a conflict between the compatibility of the intervention with teachers' responsibilities was apparent when a teacher explained that he taught an advanced class and the intervention did not align with his role:

... [the lessons are not] that interesting to kids. They teach everyday things but I want my kids to think higher, you are talking about college degrees these kids could have. The careers they use in there are not very interesting.

Teachers' comments concerning the compatibility of the intervention were also based on the characteristics of their students. For example, one teacher requested that lessons "incorporate different levels that would give us some idea of how to differentiate the lesson" for students' diverse learning needs. In this case, the teacher was indicating that the lessons did not meet the direct needs of students who were having difficulty understanding or completing the objectives set by the lessons. Another teacher pointed out the lessons were not compatible to his students' perceptions of interesting jobs. This alludes to the need to ensure that lessons are compatible with teachers' perceptions of what they know or assume to be interesting to their students. In addition, a social studies teacher commented that the lessons were similar to existing teaching practices in her subject. Although this comment suggests compatibility between her tasks and the intervention, the teacher is highlighting that the intervention is not significantly different from her previous responsibilities.

Another issue concerning compatibility was about the timing of introducing CareerStart to $7^{\text {th }}$ grade students. One teacher reported there to be a discrepancy in introducing career-related concepts in middle school rather than in high school. The teacher believed that career-related instruction would be more effective in high school when students are making career-related decisions about their coursework and future education. This comment suggests that there is a divergence in opinion between the objectives of the intervention and practitioners' compatibility with its objectives. By understanding teachers' perspectives of an intervention, specifically how adaptable and compatible the intervention is to their teaching practices and their perceptions of what students need and want, program developers may strengthen programmatic factors to better meet the objectives of the intervention. Another option may be that program developers purposively educate teachers about the conceptual basis of an intervention so they understand how an intervention may meet students' needs and wants.

\subsection{Individual Factors}

Several individual factors associated with implementation were identified in the data. The manner in which educators' perceived the intervention varied in two ways: 1) perceptions related to the need for the intervention, and 2) the intervention's effectiveness among students. Teachers had mixed perceptions of the intervention. Some teachers indicated that the lessons seemed disjointed, arbitrary, and indistinguishable from existing units, while other teachers reported that the lessons seemed relevant, and well planned. Many novice teachers perceived the lessons as supportive and a useful resource in facilitating lesson completion. They also indicated that CareerStart lessons allowed them, as one teacher stated, "to focus on a subject matter [in a] different way." Furthermore, a teacher commented, "it is a good jumping off point for discussion as we plan." Some teachers also perceived students' responses to lessons positively. One teacher stated, "I remember that I used one [lesson] and it worked. I was really surprised." After implementing an entire unit, one teacher reported, "The kids reacted positively. I noticed that the following day, after they had the career start lesson, they were more serious about their learning, which I think is very positive.”

Likewise, another teacher said she perceived the lessons brought relevancy to her classroom. In contrast, the teacher of an advanced course perceived his students to be uninterested in the lessons because they were not challenging enough. A second teacher with a similar opinion commented:

I think that if we really wanted to get these kids interested in these careers, [then we need to] give them something really interesting that will hold their mind.

She indicated that she perceived the focus of the intervention to be on traditional rather than emerging jobs. Contritely, another teacher welcomed the usefulness of bringing career content to the classroom:

A bit of application is what you want. I think it's [lessons] are useful. I think the idea is good in $7^{\text {th }}$ grade. I tell my kids they have to think about college so you have to start thinking about careers. As far 
as the program, trying to implement that is a great idea.

As displayed in this dialogue, teachers expressed mixed feelings for the intervention. While some teachers already incorporated career-relevancy into their teaching practices, other teachers experienced the program as a new and interesting resource for their students. Teachers' perceptions for the need and usefulness of an instructional strategy influences implementation fidelity.

\subsection{School Community Factors}

School community factors refer to factors that affect the implementation process of an intervention such as politics, funding, and broader state or federal policies (Durlak \& DuPre, 2008). Teachers provided comments about external factors affecting their perceptions about implementing CareerStart. For example, one teacher voiced her opinion by expressing her discontent with how her school administrators introduced the intervention as a required teaching practice method rather than a resource to use with her students. Further, although this program was introduced as a "school system directive" a second teacher indicated that it was irrelevant because:

In math the way I teach, it is automatic that I am going to talk about careers. I am already doing this.

School policies also mitigated how teachers implemented the intervention. In one case, a teacher asked permission to use a similar lesson not related to CareerStart. The school administration indicated that the new lesson had to be in conjunction with the existing language arts CareerStart lesson. Similarly, another teacher commented that,

Lessons are strictly tied into the standard course of study and if you go beyond that, you have enrichment units. [Then] you are sort of on your own.

Community factors, specifically the influence of school administrators on teachers' perceptions of an intervention, are an area of research that needs further exploration. In this study, teachers' perceptions of the intervention appear affected by the school environment in which they work.

\section{Implications and Discussion}

We conducted a qualitative investigation of factors that affected teacher fidelity of implementation of an instructional relevance intervention. Teacher implementation of CareerStart, developed by an interdisciplinary team of researchers and educators, was shown to have varying levels of fidelity as measured by teachers' reports of lessons used. Our findings have implications for further study and development of CareerStart and more broadly for the literature on fidelity of implementation in school settings.

\subsection{CareerStart Fidelity Implications}

We learned many valuable lessons in the design and implementation of CareerStart, a school-based intervention research project. Most fundamentally, we learned the lesson that all school-based researchers must learn, that working with, listening to, and valuing the experience, input, and roles of teachers in the implementation of new interventions delivered in the classroom is as important as the design, theoretical underpinnings, and content of that intervention. More valuable, however, are the details and specific lessons learned in terms of how to engage teachers and at what points in the intervention development and implementation process to maximize treatment adherence and therefore fidelity. These lessons include:

a) Early in the design process collect systematic data—observations and teacher interviews or focus groups-about the current instructional process and procedures that are being used in the classrooms that will be the target of the interventions;

b) At a midpoint in the design of an intervention, it is important to seek feedback from teachers about how the intervention can better fit and be integrated into their standard instructional approach and strategies:

c) Pilot test training materials and treatment manuals and get feedback from teachers about the clarity, ease of use, and effectiveness of those materials;

d) Once program implementation begins in a systematic and ongoing manner, monitor adherence and fidelity by collecting both qualitative and quantitative data; and finally,

e) When problems in adherence or fidelity are found, immediately get more data from teachers and seek to understand the sources of their challenge; then make program changes to address the issues they raise.

As part of this evaluation project, CareerStart was originally introduced to the first wave of sixth grade students in 2005-2006 by their teachers, who had been trained to use the fully developed lessons. In order to strengthen the fidelity of teacher implementation in the second year, which was 2006-2007, several measures were undertaken. A teacher-coach who had initially implemented CareerStart assisted in modifying the program to 
make it more easily adopted by other teachers. Second, modifications were made to the lessons informed by feedback from the teachers. Third, a system of active accountability was developed and put into practice, which produced quarterly reports of lessons taught at the teacher and school levels, including feedback on lesson quality and applicability to their students (Orthner, et al., 2010). Quantitative analysis of data collected during and after the first year has since confirmed CareerStart did not demonstrate statistically significant gains in student achievement. After consulting with teachers during and following the first year of implementation, the program was restructured to consist of 10 shorter and manageable "mini-lessons" per core subject. New personnel joined the implementation team, including a teacher who participated in the first implementation year of CareerStart. As an on-site coordinator for CareerStart, she served in this role until the end of the evaluation project. Based on the feedback received from the qualitative and quantitative data, the substantially updated program has demonstrated significant positive effects on student engagement and achievement.

\subsection{School-Based Research Fidelity Implications}

In any teacher implemented intervention study, understanding the nature of usual treatment or services is essential. Assessing the usual treatment prior to an instructional intervention implementation and evaluation is uncommon. Measuring routine teacher behavior as an element of the general intervention work is costly. Still, such procedures are important because understanding similarities and differences between pre-intervention teaching processes and new intervention processes may help educational program developers and researchers better understand the degree to which a new instructional intervention: a) overlaps with current services, b) exceeds or deviates from practitioners' roles and responsibilities, or c) undermines targeted teacher knowledge, skills, or supports.

Given that instructional strategies are implanted in the classroom, measuring teacher level of fidelity is helpful to ensure that outcomes are robust and valid in such intervention research (Tucker \& Blythe, 2008). As previously indicated, there are several methods to evaluate treatment fidelity including randomized observational checks, videotaped intervention sessions, audio taped sessions, process assessment, standardized evaluation forms, and post-session assessment. Such methods help evaluators and researchers organize and categorize barriers to teacher level fidelity, identify the effectiveness of program components, incorporate practitioners' suggestions, and distinguish variations found in program outcomes.

\subsection{Conclusion}

This study contributes to the literature on treatment fidelity in school-based intervention research. In the current study, we used qualitative methods to examine teacher factors influencing fidelity in the implementation of CareerStart. The current findings suggest teachers perceived the early version of CareerStart in three interrelated ways: 1) their perceptions of the need for the program and its effectiveness on student outcomes; 2) the degree to which the program is adaptable and compatible to their roles and responsibilities; and 3) the affects of the school environment on their perceptions of the intervention.

The current findings show potential for informing researchers of the merit and efficacy of the intervention on student outcomes. Thus, research of treatment fidelity has the potential to advance the quality of evidence-based program development and research. Further, growing demands to demonstrate the efficacy and scalability of school reform programs should drive the need for fidelity evaluations to identify variations of program effectiveness across different populations. For that reason, research on treatment fidelity adds value to existing services, especially when it helps practitioners' enhance their knowledge and skills, thus better standardizing treatment delivery.

In the main, intervention research strives to establish causal inferences between treatments and outcomes (Borrelli et al., 2005). Without careful attention to fidelity, researchers may inaccurately over- or under-estimate the effects of an intervention (Fraser et al., 2009). Further, when treatment fidelity is attended to and improved, measurement validity is advanced, statistical power increased, and face validity of treatment effects strengthened (Borrelli et al., 2005; Summerfelt, 2003). In conclusion, the central goal of the current research was to contribute to our understanding of treatment fidelity in school-based intervention research. The current study met our goal in terms of advancing the fidelity of future implementations of CareerStart and we hope other school-based researchers likewise find that the current findings inform their efforts to advance school intervention fidelity.

\section{Acknowledgements}

This work was supported by funds from the U.S. Department of Justice, Winston-Salem Foundation, Kate B. Reynolds Charitable Trust, and the Workforce Innovations partnership from the U.S. Department of Labor. The authors wish to thank Dr. Donald Martin, Superintendent of Winston-Salem/Forsyth County Schools, for his 
support and collaboration on this project.

\section{References}

Anastas, J. W. (2004). Quality in qualitative evaluation: Issues and possible answers. Research on Social Work Practice, 14(1), 57-65.

Anderman, E. A., \& Midgely, C. (1997). Changes in personal achievement goals and the perceived classroom goal structures across the transition to middle level schools. Contempiorary Educational Psychology, 22, 269-298.

Atlas.ti. (2008). Atlas (version 5.5.9) Berlin, Germany: GmbH.

Biggs, B., Vernberg, E., Twemlow, S., Fonagy, P., \& Dill, E. (2008). Teacher adherence and its relation to teacher attitudes and student outcomes in an elementary school-based violence prevention program. School Psychology Review, 37, 533-549.

Borrelli, B., Sepinwall, D., Bellg, A., Breger, R., DeFrancesco, C., Sharp, D., et al. (2005). A new tool to assess treatment fidelity and evaluation of treatment fidelity across 10 years of health behavior research. Journal of Consulting and Clinical Psychology, 73, 852-860.

Carter, E., \& Pesko, M. (2008). Social validity of peer interaction intervention strategies in high school classrooms: Effectiveness, feasibility, and actual use. Exceptionality, 16(3), 156-173. http://dx.doi.org/10.1080/09362830802198427

Chafouleas, S., Briesch, A., Riley-Tillman, T., \& McCoach, B. (2009). Moving beyond assessment of treatment acceptability: An examination of the factor structure of the usage rating Profile-Intervention (URP-I). School Psychology Quarterly, 24(1), 36-47. http://dx.doi.org/10.1037/a0015146

Coffey, A. (2007). The place of the personal in qualitative research. Qualitative Researcher, 4.

Coffey, A. \& Atkinson, P. (1996). Making sense of qualitative data complementary research strategies. Thousand Oaks: Sage Publications.

Durlak, J., \& DuPre, E. (2008). Implementation matters: A review of research on the influence of implementation on program outcomes and the factors affecting implementation. American Journal of Community Psychology, 41(3-4), 327-350.

Finn, J. (1993). School engagement and students (NCES93-147). Washington, DC: U.S. Department of Education: National Center for Education Statistics.

Fraser, M., Richman, J. M, Galinsky, M., \& Day, S. (2009). Intervention research : Developing social programs. Oxford, UK: Oxford University Press.

Fredricks, J. A., Blumenfeld, P. C, \& Paris, A. H. (2004). School engagement: Potential of the concept, state of the evidence. Review of Educational Research, 74, 59-109.

Hughes, K. L. \& Karp, M. M. (2004). School-based career development: A synthesis of the literature. Institute of Education and the Economy. Teachers College, Columbia University.

Kenny, M. E., \& Bledsoe, M. (2005). Contributions of the relational context to career adaptability among urban adolescents. Journal of Vocational Behavior, 66, 257-272.

Keller, J. (1983). Motivational design of instruction. In C. M. Reigeluth (Ed.), Instructional design theories and models: An overview of their current status (pp. 383-434). Hillsdale, NJ: Erlbaum

Lofland, J., \& Lofland, L. (1995). Analyzing social settings: A guide to qualitative observation and analysis. Belmont, CA: Wadsworth.

Martens, B., \& McIntyre, L. (2009). The importance of treatment integrity in school-based behavioral intervention. In A. Akin-Little (Ed.), Behavioral interventions in schools: Evidence-based positive strategies (1st ed., pp. 59-71). Washington, DC: American Psychological Association.

Martin, A. J. (2009). Motivation and engagement across the academic life span: A developmental construct validity study of elemntary school, high school, and university/college students. Educational and Psychological Measurement, 69, 794-824.

Means, T. B., Jonasson, D. H., \& Dwyer, F. M. (1997). Enhancing relevance: Embedded ARCS strategies versus purpose. Educational Technology Research and Development, 45(1), 5-17.

McLeod, B. D., Southam-Gerow, M. A. (2009). Conceptual and methodological issues in treatment integrity 
measurement. School Psychology Review, 28, 541-546.

Mooney, P., Epstein, M. H., Reid, R., and Nelson, J. R. (2003). Status of and trends in academic intervention research for students with emotional disturbance. Remedial and Special Education, 24(5), 273-287.

Mowbray, C. T., Holter, M. C., Teague, G. B., Bybee, D. (2003). Fidelity criteria: Development, measurement, and validation. American Journal of Evaluation, 24(3), 315-340.

O'Hare, T. (2005). Evidence-based practices for social workers: An interdisciplinary approach. Chicago: Lyceum Books.

Orthner, D. K., Akos, P., Rose, R. A., Jones-Sanpei, H., Mercado, M., Woolley, M. E. (2010). CareerStart: A middle school student engagement and academic achievement program.Children \& Schools, 32, 223-234.

Orthner, D., Jones-Sanpei, H., Rose, R., Mercado, M., \& Akos, P. (2010). CareerStart: A middle grades strategy for promoting student school engagement and academic success. Studia Sociologia, (1), 137-153.

Orthner, D.K., Jones-Sanpei, H., Akos, P., \& Rose, R., (2013). Improving middle school student engagement through career-relevant instruction in the core curriculum. Journal of Educational Research, 106, 27-38.

Orthner, D. K., Rose, R. A., \& Mercado, M. (2009). Relevance in the curriculum: The effect of teacher provided career examples on the math and reading performance of 8th grade students. 2010 SSWR Annual Conference, San Francisco, CA.

Orthner, D. K., Cook, P., Sabah, Y. \& Rosenfeld, J. (2006). Organizational Learning: A Cross-National Pilot-Test of Effectiveness in Children's Services, Evaluation and Program Planning, 29, 70-78.

Padgett, D. K. (1998). Does the glove really fit? Qualitative research and clinical social work practice. Social Work, 43. 373-381.

Perry, J. C., Liu, X., \& Pabian,Y. (2010). School engagement as a mediator of academic performance, among urban youth: The role of career preparation, parental career support, and teacher support. Counseling Psychologist, 38, 269-295.

Perry, J. C. (2008). School engagement among urban youth of color: Criterion pattern effects of vocational exploration and racial identity. Journal of Career Development, 34, 397-422.

Rose, R. A., Woolley, M. E., Akos, P., Orthner, D. K., Mercado, M., \& Jones-Sanpei, H. (2012). Increasing teachers' use of career relevant instruction: A randomized control trial of CareerStart. Educational Evaluation and Policy Analysis, 34, 295-312.

Smith, S. W., Daunic, A. P., Taylor, G. G. (2007). Treatment fidelity in applied educational research: Expanding the adoption and application of measures to ensure evidence-based practice. Education and Treatment of Children, 30(4), 121-134.

Sobeck, J. L. (2006). Lessons learned from implementing school-based substance abuse prevention curriculums. Children \& Schools, 28(2), 77-85.

Stead, M., Stradling, R., Macneil, M., Mackintosh, A., \& Minty, S. (2007). Implementation evaluation of the blueprint multi-component drug prevention programme: Fidelity of school component delivery. Drug and Alcohol Review, 26, 653-664. http://dx.doi.org/10.1080/0959230701613809

Stein, M., Berends, M., Fuchs, D., McMaster, K., Saenz, L., Yen, L., et al. (2008). Scaling up an early reading program: Relationships among teacher support, fidelity of implementation, and student performance across different sites and years. Educational Evaluation and Policy Analysis, 30, 368-388. http://dx.doi.org/10.3102/0162373708322738

Summerfelt, W. T. (2003). Program strength and fidelity in evaluation. Applied Developmental Science, 7(2), 55-61.

Tucker, A. R. \& Blythe, B. (2008). Attention to treatment fidelity in social work outcomes: A review of the literature from the 1990s. Social Work Research, 32(3), 185-190.

Waltz, J. (1993). Testing the integrity of a psychotherapy protocol: Assessment of adherence and competence. Journal of Consulting and Clinical Psychology, 61, 620-630.

Wehby, J. H., Maggin, D. M., Partin, T. M., \& Robertson, R. (2011). The impact of working alliance, social validity, and teacher burnout on implementation fidelity of the good behavior game. School Mental Health. 
Weiss, R. (1994). Learning from strangers: The art and method of qualitative interview studies. New York, NY: The Free Press.

Wigfield, A., \& Tonks, S. (2002). Adolescents' expectancies for success and achievement task values during middle and high school years. In F. Pajares \& T. Urdan (EDs.) Academic motivation of adolescents (pp. 53-82). Greewich, CT: Information Age.

Wolf, M. (1978). Social validity: The case for subjective measurement or how applied behavior analysis is finding its heart. Journal of Applied Behavior Analysis, 11(2), 203-214.

Woolley, M. E. (2007). Advancing a Positive School Climate for Students, Families, and Staff. In C. Franklin, M. B. Harris, \& P. Allen-Meares (Eds.), The School Services Sourcebook: A Guide for School-Based Professionals (pp. 777-783). New York, NY: Oxford Press.

Woolley, M. E, \& Bowen, G. L. (2007). In the context of risk: Supportive adults and the school engagement of middle school students. Family Relations, 56, 92-104.

Woolley, M. E. \& Grogan-Kaylor, A. (2006). Protective family factors in the context of neighborhood: Promoting positive school outcomes. Family Relations, 55, 95-106.

Zvoch, K. (2009). Treatment fidelity in multisite evaluation: A multilevel longitudinal examination of provider adherence status and change. American Journal of Evaluation, 30(1), 44-61.

\section{(c) EY}

This work is licensed under a Creative Commons Attribution 3.0 License. 